\title{
Oil Price Shocks and Uncertainty: How stable is their relationship over time?
}

\author{
Stavros Degiannakis ${ }^{1,2}$, George Filis, ${ }^{3, *}$ and Sofia Panagiotakopoulou ${ }^{1}$ \\ ${ }^{1}$ Department of Economics and Regional Development, Panteion University of Social and \\ Political Sciences, 136 Syggrou Avenue, 17671, Greece. \\ ${ }^{2}$ Postgraduate Department of Business Administration, Hellenic Open University,
} Aristotelous 18, 26 335, Greece.

${ }^{3}$ Department of Accounting, Finance and Economics, Bournemouth University, 89

Holdenhurst Road, BH8 8EB, Bournemouth, UK

*Corresponding author: gfilis@bournemouth.ac.uk

\begin{abstract}
This paper investigates the time-varying relationship between economic/financial uncertainty and oil price shocks in the US. A structural VAR (SVAR) model and a time-varying parameter VAR (TVP-VAR) model are estimated, using six indicators that reflect economic and financial uncertainty. The findings of the study reveal that static frameworks (SVAR) do not show the full dynamics of the oil price shocks effects to the US economic/financial uncertainty. This is owing to the evidence provided by the time-varying framework (TVP-VAR), which convincingly shows that uncertainty responses to the three oil price shocks are heterogeneous both over time and over the different oil price shocks. In particular, uncertainty responses seem to experience a shift in the post global financial crisis period. Thus, the conventional findings that economic fundamentals response marginally, positively or negatively to supply-side, aggregate demand and oil specific demand shocks, respectively, do not necessarily hold at all periods. Rather, they are impacted by the prevailing economic conditions at each time period. The findings are important to policy makers and investors, as they provide new insights on the said relationships.
\end{abstract}

Keywords: Economic policy uncertainty, financial uncertainty, realized volatility, oil price shock, SVAR, TVP-VAR, US.

JEL: C32, C51, G15, Q40. 


\section{Introduction}

Focusing on the US economy, the aim of this paper is to investigate the timevarying effects of oil price shocks, namely supply-side, aggregate demand and oil specific demand shocks, on economic uncertainty. The study focuses on different types of economic-wide uncertainty, which capture the different sectors of an economy, namely macroeconomic-related, policy-related, commodity-related and financial-related uncertainty. In the context of this paper we define economic-wide uncertainty as the unknown outcome in the future economic, policy and financial markets conditions of the country, when these are confronted with unanticipated shocks in oil prices.

The interest on the drivers of economic uncertainty has reemerged since the last financial crisis of 2007-09, the ongoing European debt crisis, the oil price collapse since 2014 and more recently the Trump's victory in the US elections and the Brexit vote in the 2016 UK's referendum (see, inter alia, Bloom, 2009; Baum et al., 2010; Bachmann et al., 2010; Popescu and Smets, 2010; Antonakakis et al., 2013; New York Times, 2016; Bloomberg, 2017; Caggiano et al., 2017).

Interestingly enough, though, the literature has remained relatively silent on the effects of oil prices on economic-wide uncertainty, despite the ample evidence on the effects of oil prices (i) on the economy since the 1980s and the seminal paper by Hamilton (1983), as well as (ii) on the financial markets, since the seminar paper by Jones and Kaul (1996) ${ }^{1}$. The wealth of literature has established that oil prices affect the wider economy, via their influence on productivity, inflation or unemployment ${ }^{2}$.

Nevertheless, examining the effects of oil prices on economic uncertainty is rather important, given the effects of the latter to the wider economy, as established by Bernanke (1983), Marcus (1981) and Rodrik (1991) among others. More specifically, examining the sources of economic uncertainty is of major importance as the latter affects the business cycle through its influence on economic activity (Pindyck, 1990; Bloom, 2009; Kang et al., 2014; Visco, 2017), either via household consumption decisions or firm investments decisions. Put it simply, the higher the economic uncertainty the lower the household consumption and the higher the delays in capital investments. The impact of oil price shocks on investment uncertainty is

\footnotetext{
${ }^{1}$ See, Sadorsky (1999), Park and Ratti (2008), Filis (2010), Cunado and de Gracia (2014), Angelidis et al. (2015), Boldanov et al. (2016) and Antonakakis et al. (2017), among many others.

${ }^{2}$ See, inter alia, Hamilton (1988, 1996), Hooker (1996), Abel and Bernanke (2001), Lee and Ni (2002), Hooker (2002), Bernanke (2006), Hamilton (2008, 2009), Lippi and Nobili (2012).
} 
also documents by more recent studies, such as those by Elder and Serletis (2010), Ratti et al. (2011) and Rahman and Serletis (2011). Although the focus on this paper is to identify the direct effects of oil price shocks on economic-wide uncertainty, we should not lose sight of the fact that these effects might propagate indirectly via the inflation, production or even the size of the public sector channels ${ }^{3}$. The examination of these indirect channels, though, falls beyond the scope of the current paper.

Turning our attention to the linkages between oil prices and financial-related uncertainty, the literature is extremely scarce. It is only Degiannakis et al. (2014) who provide evidence that oil price shocks exercise an effect on stock market volatility. The channel by which these effects are materialized is based on the fact that unanticipated changes in the prices of oil lead to abrupt fluctuations in the future firms' cash flows, which then lead to higher uncertainty about the firms' stock prices. Under the valid assumption that most listed firms will be impacted by such unanticipated oil price changes, we maintain that oil price shocks lead to higher stock market volatility.

Finally, there is an emerging strand in the energy finance literature which is motivated by Filis et al. (2011), Degiannakis et al. (2013), Broadstock and Filis (2014), Bekiros et al. (2015) and Aloui et al. (2016), among other, that show timevarying spillover effects between the aforementioned oil price shocks and economic policy uncertainty. For instance, Antonakakis et al. (2014) report that the aggregate demand oil price shocks mainly lead to a reduction in economic policy uncertainty, whereas oil specific demand shocks and supply-side shocks do not exhibit any strong spillover effects.

Against this backdrop, we maintain that it is important to extend the studies by Kang and Rati (2013), Bekiros et al. (2015), Aloui et al. (2016), and Kang et al. (2017) and to assess how oil price shocks could also trigger changes in other sources

\footnotetext{
${ }^{3}$ For instance, recent literature shows that when there is an increase in the price of oil, this causes inflationary pressures and lower household consumption in an oil-importing country, which forces the monetary authority to face a trade-off of either stabilizing inflation or output gap, leading to higher uncertainty (Natal, 2012; Montoro, 2012). In addition, El Anshasy and Bradley (2012) claim that higher oil prices lead to greater government size for the oil-exporting countries. Nevertheless, an increased size of the public sector raised issues in terms of the efficient operation of the government, as also emphasized by Antonakakis et al. (2014), leading to further economic uncertainty. Along a similar vein, Kang and Rati (2013), Antonakakis et al. (2014) and Kang et al. (2017) maintain that policyrelated uncertainty is also affected by oil price shocks. This is rather expected based on the aforementioned transmission channels. For instance, the trade-off that the monetary policy is faced with in the case of oil price increases, leads to both uncertainty in terms of the outcome in the real economy, as well as uncertainty as to whether policy decisions will be successful in stabilizing the economy.
} 
of economic-wide uncertainty, such as commodity-related and macroeconomicrelated, rather than solely on economic policy and financial uncertainty, which is the main focus of the existing literature. This paper aims to fill this void.

The contribution of this paper can be described succinctly. First, it adds to the limited empirical findings on the linkages between oil price shocks and several economic-wide uncertainties. Second, we investigate for the first time in the literature whether the responses of these economic-wide uncertainty indicators to the three oil price shocks are time-varying. Put it simply, this paper analyses the effects of the different oil price shocks on a wide range of uncertainty measures in a Structural VAR framework, both constant and time-varying. To do so, this study concentrates on six key US economic uncertainty indicators for the period January 1994 to March 2015 and uses a structural VAR (SVAR) model, as well as, a Time-Varying Parameter VAR (TVP-VAR).

Our results can be outlined as follows. The responses of the uncertainty indicators to the three oil price shocks, as these were estimated by the SVAR model, reveal that oil supply shocks do not exercise any significant impact on uncertainty indicators. Furthermore, we find that the two demand-side oil shocks trigger lower uncertainty. More importantly, though, through the TVP-VAR model we show that impulse responses of the uncertainty indices to the three oil price shocks are not constant over time, but rather they vary over time. The time-varying impulse responses show that uncertainty indices exhibit heterogeneous responses to all three shocks, as well as, during different time periods. More specifically, we show that the behaviour of responses changes in the post global financial crisis period, suggesting a shift in the relationship between oil shocks and uncertainty indicators.

The rest of the paper is structured as follows. Section 2 describes the data employed in this study, whereas Section 3 details the methodology. The empirical findings of the research are presented in Section 4, whereas Section 5 summarises the results and concludes the paper.

\section{Data Description}

In this study we employ world oil production (in thousand barrels, PROD), Lutz Kilian's global real economic activity index $(\mathrm{GEA})^{4}$ and Brent crude oil price

\footnotetext{
${ }^{4}$ The Kilian's index became popular selection for the real economic activity worldwide as it captures business cycle fluctuations in global base about commodity markets of industrial sector and is used by
} 
returns (ROIL), which are used for the construction of the three oil price shocks (supply-side, aggregate demand and oil specific demand shocks). We also use six measures of economic and financial uncertainty in the US, which capture macroeconomic-related (JMU), policy-related (EPU), commodity-related (OCV and ORV) and financial-related (EMU and VIX) uncertainty.

More specifically, we use (i) Jurado's et al. (2015) macroeconomic uncertainty index (JMU), which expresses the common volatility of the unforecastable components of 132 macroeconomic indicators; (ii) The Economic Policy Uncertainty Index (EPU), which is constructed based on three components, i.e. newspaper articles of the ten largest newspapers of the US, the temporary provisions of the tax code expiration of the US and the factor of disagreement between the opinions of economic forecasters. Thus, EPU combines the different sources of uncertainty which are linked to the policy making and political conditions in an economy, without explicitly considering the country's macroeconomic fundamentals; (iii) The Equity Market Uncertainty Index (EMU), which is based on an automated text-search process from Access World News's NewsBank service news articles that contain terms related to "uncertainty", "economy", "stock price" and "equity market"; (iv) The Implied Volatility Index of S\&P500 (VIX), which is often characterized as the "fear index" and it is the leading measure of market expectations of the implied volatility of S\&P500 index options over the upcoming 30-day period; and (v) the Conditional Oil Price Volatility (OCV), which is a measure of commodity uncertainty. We approximate commodity-related uncertainty with the oil price volatility, given that oil is one of the most important traded commodities in the world and one of the most important production inputs. For this particular uncertainty indicator, we construct an additional oil price volatility series (vi), namely the Realized Oil Price Volatility (denoted as ORV) for robustness purposes ${ }^{5}$. The usage of these two volatility series is justified by the fact that realized volatility is a more precise and less noisy estimator, according to the literature (e.g. Andersen and Bollerslev, 1998), but it requires no-freely available data for its construction, which are not always available to researchers. On the other hand, the conditional volatility is a widely applied and accepted volatility estimator and requires daily data.

many authors such as; Apergis and Miller (2009), Baumeister and Kilian (2014) and Alquist and Kilian (2010), among others.

5 We have also considered the volatility of the CRB Commodity index and the results remain qualitatively similar. 
All data span from January 1994 to March 2015 and they are in monthly frequency, with only exception the data used for the OCV and ORV. The EPU and EMU have been extracted from Baker et al. (2016) ${ }^{6}$. In addition, Brent crude oil prices and the world oil production are obtained from the Energy Information Administration. We also obtain US CPI data, available from the Bureau of Labor Statistics of the United States, which are used to convert Brent oil prices in real terms. The GEA is taken from Lutz Kilian's personal site $^{7}$, whereas the VIX come from FRED database. Finally, the JMU is retrieved from Ludvigson's personal site ${ }^{8}$.

For the construction of the OCV we collect daily Brent crude oil prices from Energy Information Administration, whereas tick-by-tick data of Brent crude oil prices, which are collected for the ORV, are obtained from TickData. For the latter the data span from August 2003 to March 2015, due to unavailability of longer period of the tick-by-tick data. The construction of the two oil price volatility series is presented in Sections 3.1 and 3.2. We do not consider implied volatility given that this is not available for the Brent crude oil prices.

We convert oil production data in its first-log differences, whereas GEA and all uncertainty indices are expressed in levels.

\section{Methodology}

\subsection{Oil price realized volatility}

Let us consider as $\log P_{t_{j}}$ the observed Brent crude oil $\log$-price at trading day $t$ and $j$ intra-day point. For $j=1, . ., \tau$ equidistant intervals at each trading day, Andersen and Bollerslev (1998) provided evidence that the daily realized volatility is estimated to be the sum of squared intra-day returns:

$$
D R V_{t}^{(\tau)}=\sqrt{\sum_{j=1}^{\tau}\left(\log P_{t_{j}}-\log P_{t_{j-1}}\right)^{2}}
$$

The realized volatility converges in probability to the integrated volatility, $I V_{t} \equiv$ $\int \sigma^{2}(t) d t$, as the number of sub-intervals tends to infinity, $\tau \rightarrow \infty$. However, the

\footnotetext{
${ }^{6}$ In more details, the US policy uncertainty index appears at http://www.policyuncertainty.com/us_monthly.html and the equity market uncertainty index appears at http://www.policyuncertainty.com/equity_uncert.html.

${ }^{7}$ Lutz Kilian's GEA index comes from http://www-personal.umich.edu/ lkilian/paperlinks.html and especially from the link: Updated version of the index of global real economic activity in industrial commodity markets, proposed in "Not all oil price shocks are alike ...", monthly percent deviations from trend, 1968.1-2015.9.

${ }^{8} \mathrm{https}: / / \mathrm{www}$. sydneyludvigson.com/data-and-appendixes.
} 
microstructure frictions (i.e. discreteness of the data, transaction costs, taxes, regulatory costs, properties of the trading mechanism, bid-ask spreads, ect.) add more noise to the estimated volatility when the sampling frequency converges on zero. Thus, there is a trade-off between the bias that is inserted in the realized volatility measure and its accuracy.

The daily variance, $\left(\log P_{t}-\log P_{t-1}\right)^{2}$, can be decomposed into the intra-day variance, $D R V_{t}^{2(\tau)}$, and the intra-day autocovariance, $\sum_{j=1}^{\tau-1} \sum_{i=j+1}^{\tau}\left(\log P_{t_{i}}-\right.$ $\left.\log P_{t_{i-1}}\right)\left(\log P_{t_{i-j}}-\log P_{t_{i-j-1}}\right)$ :

$$
\begin{gathered}
\left(\log P_{t}-\log P_{t-1}\right)^{2}= \\
D R V_{t}^{2(\tau)}+2 \sum_{j=1}^{\tau-1} \sum_{i=j+1}^{\tau}\left(\log P_{t_{i}}-\log P_{t_{i-1}}\right)\left(\log P_{t_{i-j}}-\log P_{t_{i-j-1}}\right) .
\end{gathered}
$$

The intra-day autocovariance represents the bias that is induced in the realized volatility measure, with $E\left(\left(\log P_{t_{i}}-\log P_{t_{i-1}}\right)\left(\log P_{t_{i-j}}-\log P_{t_{i-j-1}}\right)\right)=0$, for $j \neq 0$. Fang (1996) and Andersen et al. (2006) suggested the optimal sampling frequency being the highest frequency that minimises the autocovariance bias. In the case of Brent crude oil the $\left(\sum_{j=1}^{\tau-1} \sum_{i=j+1}^{\tau}\left(\log P_{t_{i}}-\log P_{t_{i-1}}\right)\left(\log P_{t_{i-j}}-\log P_{t_{i-j-1}}\right)\right)$ is minimized at $\tau=23$. Hence, the optimal sampling frequency is defined in 23 minutes.

Furthermore, it is well established that when markets are closed, i.e. during night-time periods, holidays, and weekends, information still flows. Hansen and Lunde (2005), in order to account for changes in the asset prices during the hours that the market is closed, proposed to adjust the intra-day volatility with the close-to-open inter-day volatility, as:

$$
D R V_{t,(H L)}^{(\tau)}=\sqrt{\omega_{1}\left(\log P_{t_{1}}-\log P_{t-1_{\tau}}\right)^{2}+\omega_{2} \sum_{j=2}^{\tau}\left(\log P_{t_{j}}-\log P_{t_{j-1}}\right)^{2}}
$$

where ${ }^{9}$ the weights $\omega_{1}$ and $\omega_{2}$ are such that minimise the difference between the realized volatility and the integrated volatility, i.e. $\min E\left(D R V_{t,(H L)}^{2(\tau)}-I V_{t}\right)^{2}$. Of course, the $I V_{t}$ is unobservable. Thus, Hansen and Lunde (2005) proposed to solve $\min V\left(D R V_{t,(H L)}^{2(\tau)}\right), \quad$ as they have stated that $\arg \min E\left(D R V_{t,(H L)}^{2(\tau)}-I V_{t}\right)^{2}=$

\footnotetext{
${ }^{9}$ The subscript $(H L)$ denotes the $D R V_{t}$, measure according to Hansen and Lunde's adjustment.
} 
$\arg \min V\left(D R V_{t,(H L)}^{2(\tau)}\right)$. Finally, the annualised monthly realized volatility series, $O R V_{t}^{(m)}$, is constructed as:

$$
O R V_{\mathrm{t}}^{(\mathrm{m})}=100 \sqrt{12 \sum_{t=1}^{22} D R V_{t,(H L)}^{2(\tau)}}
$$

\subsection{Oil price conditional volatility}

We estimate the conditional volatility of the oil daily log-returns using Ding's et al. (1993) APARCH model, in the spirit of Degiannakis et al. (2014). The APARCH model is estimated as:

$$
\begin{gathered}
y_{t}=c_{0}+\varepsilon_{t} \\
\varepsilon_{t}=\sigma_{t} z_{t} \\
\sigma_{t}^{\delta}=a_{0}+a_{1}\left(\left|\varepsilon_{t-1}\right|-\gamma_{1} \varepsilon_{t-1}\right)^{\delta}+b_{1} \sigma_{t-1}^{\delta} \\
z_{t}^{\text {i.i.d. }} \sim T(0,1 ; v) \\
f_{(t)}\left(z_{t} ; v\right)=\frac{\Gamma((v+1) / 2)}{\Gamma(v / 2) \sqrt{\pi(v-2)}}\left(1+\frac{z_{t}^{2}}{v-2}\right)^{-\frac{v+1}{2}},
\end{gathered}
$$

where $a_{0}>0, \delta>0, b_{1} \geq 0, a_{1} \geq 0$ and $-1<\gamma_{1}<1, v>2$.

The APARCH model is considered as one of the best models for estimating conditional volatility (for technical details, please see Xekalaki and Degiannakis, 2010).

We compute the annualised monthly conditional volatility, $O C V_{t}^{(m)}$, as:

$$
O C V_{\mathrm{t}}^{(m)}=100 \sqrt{12 \sum_{t=1}^{22} \sigma_{t / t-1}^{2}},
$$

where $\sigma_{t / t-1}^{2}$ denotes the daily conditional variance for the $t=1, \ldots, 22$ trading days of month $m$.

\subsection{Structural VAR framework}

Prior to the examination of the time-varying responses of the uncertainty indicators to oil price shocks, we employ a Structural Vector Autoregressive (SVAR) model in order to explore the impact of oil price shocks (supply-side, aggregate demand and oil specific demand shocks) on the respective six uncertainty indices (UNCERT), based on the full sample. The supply-side shocks (SS) reflect unexpected changes in world oil production of crude oil (PROD), the aggregate demand shocks 
(ADS) are identified from global real economic activity (GEA) and oil specific demand shocks (SDS) are estimated from changes in crude oil prices (ROIL). The generic name of uncertainty series is UNCERT. Our SVAR model has been adopted by Kilian and Park (2009).

The standard representation of a general $\mathrm{p}^{\text {th }}$ order SVAR model is expressed in the following form:

$$
\mathbf{A}_{0} \mathbf{y}_{\mathrm{t}}=\mathbf{c}_{0}+\sum_{\mathrm{i}=1}^{\mathrm{p}} \mathbf{A}_{\mathrm{i}} \mathbf{y}_{\mathrm{t}-\mathrm{i}}+\boldsymbol{\varepsilon}_{\mathrm{t}},
$$

where, $\mathbf{A}_{0}$ represents the $[4 \times 4]$ matrix that summarizes the contemporaneous relationship between the variables of the model, $\mathbf{c}_{0}$ is a $[4 \times 1]$ vector of constants, $\mathbf{A}_{\mathrm{i}}$ are $[4 \times 4]$ autoregressive coefficient matrices and $\boldsymbol{\varepsilon}_{\mathrm{t}}$ is a $\left[\begin{array}{lll}4 & \times 1\end{array}\right]$ vector of error terms "structural shocks" assumed to have zero covariance and be serially uncorrelated, $E\left(\varepsilon_{\mathrm{t}}\right)=0, E\left(\varepsilon_{\mathrm{t}} \boldsymbol{\varepsilon}_{\mathrm{t}}^{\prime}\right)=\boldsymbol{D}$ and $E\left(\varepsilon_{\mathrm{t}} \boldsymbol{\varepsilon}_{\mathrm{t}-\mathrm{i}}^{\prime}\right)=\mathbf{0}$. Finally, $\mathbf{y}_{\mathrm{t}}$ is a $[4 \times 1]$ vector of 4 endogenous variables and specifically $\mathbf{y}_{\mathrm{t}}=\left[P R O D_{t}, G E A_{t}, R O I L_{t}, U N C E R T_{t}\right]^{\prime}$, where $U N C E R T_{t}$ refers each time at one of the six uncertainty indicators that are considered in this study.

The variance-covariance matrix of the structural shocks where all the elements off the main diagonal are zero is typically normalized that:

$$
E\left(\boldsymbol{\varepsilon}_{\mathrm{t}} \boldsymbol{\varepsilon}_{\mathrm{t}}^{\prime}\right)=\boldsymbol{D}=\left[\begin{array}{cccc}
\sigma_{1}^{2} & 0 & 0 & 0 \\
0 & \sigma_{2}^{2} & 0 & 0 \\
0 & 0 & \sigma_{3}^{2} & 0 \\
0 & 0 & 0 & \sigma_{4}^{2}
\end{array}\right]
$$

The reduced form of our structural model is estimated by multiplying both sides with $\mathbf{A}_{0}^{-1}$ as that:

$$
\mathbf{y}_{\mathrm{t}}=\mathbf{B}_{0}+\sum_{\mathrm{i}=1}^{\mathrm{p}} \mathbf{B}_{\mathrm{i}} \mathbf{y}_{\mathrm{t}-\mathrm{i}}+\mathbf{e}_{\mathrm{t}}
$$

where, $\mathbf{B}_{0}=\mathbf{A}_{0}^{-1} \mathbf{c}_{0}, \quad \mathbf{B}_{\mathrm{i}}=\mathbf{A}_{0}^{-1} \mathbf{A}_{\mathrm{i}}$ and $\boldsymbol{e}_{\mathrm{t}}=\mathbf{A}_{0}^{-1} \boldsymbol{\varepsilon}_{\mathrm{t}}$, i.e. $\boldsymbol{\varepsilon}_{\mathrm{t}}=\mathbf{A}_{0} \boldsymbol{e}_{\mathrm{t}}$. The reducedform errors $\boldsymbol{e}_{\mathrm{t}}$ are linear combinations of the structural errors $\boldsymbol{\varepsilon}_{\mathrm{t}}$, with a covariance matrix of the form can be expressed as $E\left(\boldsymbol{e}_{\mathrm{t}} \boldsymbol{e}_{\mathrm{t}}^{\prime}\right)=\mathbf{A}_{0}^{-1} \mathbf{D} \mathbf{A}_{0}^{-1 \prime}$.

In order to obtain the structural shocks we need to impose suitable short-run restrictions on $\mathbf{A}_{0}$, as follows: 


$$
\left[\begin{array}{c}
\varepsilon_{1, \mathrm{t}}^{S S} \\
\varepsilon_{2, \mathrm{t}}^{\mathrm{ADS}} \\
\varepsilon_{3, \mathrm{t}}^{\mathrm{SDS}} \\
\varepsilon_{4, \mathrm{t}}^{\mathrm{UNS}}
\end{array}\right]=\left[\begin{array}{cccc}
\mathrm{a}_{11} & 0 & 0 & 0 \\
\mathrm{a}_{21} & \mathrm{a}_{22} & 0 & 0 \\
\mathrm{a}_{31} & \mathrm{a}_{32} & \mathrm{a}_{33} & 0 \\
\mathrm{a}_{41} & \mathrm{a}_{42} & \mathrm{a}_{43} & \mathrm{a}_{44}
\end{array}\right]\left[\begin{array}{c}
\mathrm{e}_{1, \mathrm{t}}^{\mathrm{PROD}} \\
\mathrm{e}_{2, \mathrm{t}}^{\mathrm{GEA}} \\
\mathrm{e}_{3, \mathrm{t}}^{\mathrm{ROIL}} \\
\mathrm{e}_{4, \mathrm{t}}^{\mathrm{UNERT}}
\end{array}\right]
$$

In which $\varepsilon_{1, \mathrm{t}}^{\mathrm{SS}}$ captures the supply side shocks $(\mathrm{SS}), \varepsilon_{2, \mathrm{t}}^{\mathrm{ADS}}$ reflects the aggregate oil demand shocks (ADS), $\varepsilon_{3, \mathrm{t}}^{\mathrm{SDS}}$ denotes the oil specific demand shocks (SDS) and $\varepsilon_{4, \mathrm{t}}^{\mathrm{UNS}}$ measures the uncertainty shocks (UNS). We should emphasize here that we run six separate SVAR models, one for each uncertainty indicator ${ }^{10}$. Once again, we should highlight that the short-term restrictions which are necessary in the context of structural vector autoregressive models are based on Kilian and Park (2009).

In particular, according to Kilian and Park (2009), oil production does not respond contemporaneously to shocks in oil demand and oil prices, due to the high adjustment costs. By contrast, changes in the world oil production have an immediate effect on oil demand and they are instantly captured in oil price fluctuations, hence both aggregate demand and oil prices are allowed to receive contemporaneous effects from changes in the world oil production. Furthermore, given the time lag that is required for the global economy to respond to changes in oil prices, we do not allow for a contemporaneous effects on the global economic activity to changes in oil prices. However, shocks in aggregate economic activity are anticipated to trigger immediate (and thus contemporaneous) effects on oil prices. Finally, we posit that economic/financial uncertainty responds contemporaneously to all aforementioned oil price shocks, whereas the reverse does not hold true.

\subsection{Time-Varying Parameter Vector AutoRegression}

In the time-varying parameter VAR model (TVP-VAR):

$$
\mathbf{y}_{\mathrm{t}}=\mathbf{B}_{0, \mathrm{t}}+\sum_{\mathrm{i}=1}^{\mathrm{p}} \mathbf{B}_{\mathrm{i}, \mathrm{t}} \mathbf{y}_{\mathrm{t}-\mathrm{i}}+\mathbf{e}_{\mathrm{t}}
$$

the vector $\mathbf{B}_{0, \mathrm{t}}$ of Eq. (9) is a [4 $\times 1$ ] vector of time-varying coefficients, whereas $\mathbf{B}_{\mathrm{i}, \mathrm{t}}=\left[\begin{array}{ccc}\beta_{1,1, i, t} & \cdots & \beta_{1,4, i, t} \\ \vdots & \ddots & \vdots \\ \beta_{4,1, i, t} & \cdots & \beta_{4,4, i, t}\end{array}\right]$ are matrices of time-varying coefficients

\footnotetext{
${ }^{10}$ The length of the lags for the SVAR models is determined by Akaike information criterion (AIC). The AIC criterion for each of the six SVAR models is the following; model with JMU with three lags, models with EPU, EMU, VIX and OCV with two lags and model with ORV with five lags. All SVAR models satisfy the stability condition. We do not use all six indicators in one SVAR model, given that we are primarily concerned with the effects of oil price shocks and each of the uncertainty indicators, rather than the interactions among the sources of uncertainty.
} 
and $\boldsymbol{e}_{\mathrm{t}} \sim N\left(\mathbf{0}, \boldsymbol{\Omega}_{t}\right)$. The time-varying covariance matrix is recursively identified by the decomposition:

$$
\boldsymbol{\Omega}_{t}=\mathbf{A}_{\mathrm{t}}^{-1} \boldsymbol{\Sigma}_{t} \boldsymbol{\Sigma}_{t}^{\prime}\left(\mathbf{A}_{\mathrm{t}}^{-1}\right)^{\prime},
$$

where $\mathbf{A}_{\mathbf{t}}$ is a lower-triangular matrix with the diagonal elements equal to one, and $\boldsymbol{\Sigma}_{t}=\operatorname{diag}\left(\sigma_{1, t}, \ldots, \sigma_{4, t}\right)$. All the elements of the time-varying matrices are stacked in row vectors such as:

$$
\begin{gathered}
\boldsymbol{\alpha}_{t}=\left(\alpha_{1, t}, \ldots, \alpha_{6, t}\right)^{\prime}, \\
\boldsymbol{\beta}_{t}=\left(\beta_{1,1,1, t}, \ldots, \beta_{4,4,1, t}, \ldots, \beta_{1,1, p, t}, \ldots, \beta_{4,4, p, t}\right)^{\prime}, \\
\boldsymbol{\sigma}_{t}=\left(\log \left(\sigma_{1, t}^{2}\right), \ldots, \log \left(\sigma_{4, t}^{2}\right)\right)^{\prime} .
\end{gathered}
$$

The time-varying parameters follow the random walk process:

$$
\begin{aligned}
& \boldsymbol{\alpha}_{t}=\boldsymbol{\alpha}_{t-1}+\boldsymbol{u}_{(a), t}, \boldsymbol{\alpha}_{t} \sim N\left(\boldsymbol{\mu}_{(\alpha)}, \boldsymbol{\Sigma}_{(\alpha)}\right), \\
& \boldsymbol{\beta}_{t}=\boldsymbol{\beta}_{t-1}+\boldsymbol{u}_{(\beta), t}, \boldsymbol{\beta}_{t} \sim N\left(\boldsymbol{\mu}_{(\beta)}, \boldsymbol{\Sigma}_{(\beta)}\right), \\
& \boldsymbol{\sigma}_{t}=\boldsymbol{\sigma}_{t-1}+\boldsymbol{u}_{(\sigma), t}, \boldsymbol{\sigma}_{t} \sim N\left(\boldsymbol{\mu}_{(\sigma)}, \boldsymbol{\Sigma}_{(\sigma)}\right),
\end{aligned}
$$

where $\left[\begin{array}{l}\boldsymbol{u}_{(a), t} \\ \boldsymbol{u}_{(\beta), t} \\ \boldsymbol{u}_{(\sigma), t}\end{array}\right] \sim N\left(\mathbf{0},\left[\begin{array}{ccc}\boldsymbol{\Sigma}_{(a)} & \mathbf{0} & \mathbf{0} \\ \mathbf{0} & \boldsymbol{\Sigma}_{(\beta)} & \mathbf{0} \\ \mathbf{0} & \mathbf{0} & \boldsymbol{\Sigma}_{(\sigma)}\end{array}\right]\right)$. The reduced form of the structural model can be regarded as a nested model of the TVP-VAR ${ }^{11}$ for $\boldsymbol{\Sigma}_{(\alpha)}=\boldsymbol{\Sigma}_{(\beta)}=$ $\boldsymbol{\Sigma}_{(\sigma)}=\mathbf{0}$. Denoting as $\left(\boldsymbol{\Sigma}_{(\alpha)}\right)_{i}$ the $i^{\text {th }}$ diagonal element of matrix $\boldsymbol{\Sigma}_{(\alpha)}$, the prior distributions employed are: $\left(\boldsymbol{\Sigma}_{(\alpha)}\right)_{i}^{-2} \sim G(2,0.01), \quad\left(\boldsymbol{\Sigma}_{(\beta)}\right)_{i}^{-2} \sim G(20,0.01)$ and $\left(\boldsymbol{\Sigma}_{(\sigma)}\right)_{i}^{-2} \sim G(2,0.01)$, where $G(.,$.$) is the Gamma distribution. The lag length of the$ TVP-VAR models is selected according to the highest marginal likelihood as suggested by Nakajima et al. (2011) ${ }^{12}$. The prior distribution for the initial values of the row vectors $\boldsymbol{\alpha}_{t}, \boldsymbol{\beta}_{t}$ and $\boldsymbol{\sigma}_{t}$ is the normal with the mean and variance set equal to the OLS estimates using the dataset of the first 5 years. The Gibbs sampler of the Markov chain Monte Carlo (MCMC) method $^{13}$ is implemented to generate samples from the posterior distributions of $\boldsymbol{\alpha}_{t}, \boldsymbol{\beta}_{t}$, and $\boldsymbol{\sigma}_{t}$. The MCMC algorithm is presented in detail in Nakajima (2011). The MCMC algorithm has been implemented with 25000 iterations (after a 2500 burn-in). A higher number of iterations was also

\footnotetext{
${ }^{11}$ See also Gali and Gambetti (2015).

${ }^{12}$ Four lags for the models with EMU, EPU and JMU, five lags for the models with ORV and OCV and seven lags for the model with VIX.

${ }^{13}$ Technical information for the Bayesian estimation of the models is available in Nakajima (2011), Koop and Korobilis (2010) and Primiceri (2005).
} 
employed but it required substantially more time for the estimation of the parameters with no changes in the parameters' estimations.

\section{Empirical Results}

\subsection{Descriptive statistics}

Figures 1 to 2 plot the evolution of all the data series over time. The figures depict the peaks and troughs of world oil production, global real economic activity, oil log-returns and uncertainty measures. The selected time period of data includes the early-2000 recession in the US, the Global Financial Crisis (GFC) of 2007-09 and the ongoing European debt crisis. As evident by Figures 1 and 2 most series exhibit either unprecedented peaks or troughs during the GFC. Interestingly, the EMU reached its unprecedented levels during the early-2000 recession and EPU in 2011 and 2013, which are the periods characterised by the debt ceiling dispute and the fears for government shutdown, respectively. Another notable observation is that GEA fluctuates at really low levels in the latter part of our sample period, suggesting that the global economy does not show signs of recovery. It is interesting that the GEA value in this latter period is even lower than its value during the GFC.

\section{[FIGURE 1 HERE]}

\section{[FIGURE 2 HERE]}

Table 1 presents the descriptive statistics of the chosen variables. It is evident that the most volatile uncertainty index is the EMU, followed by the VIX index, in terms of the coefficient of variation. Interestingly enough, the least volatile uncertainty series is the JMU. Furthermore, as depicted by the skewness, kurtosis and Jarque-Bera test, none of the series under consideration are normally distributed, where most series exhibit a leptokurtic distribution. In addition, all uncertainty indicators are positively skewed, indicating that they exhibit instances of extreme uncertainty conditions. Finally, according to the ADF test all variables are stationary.

[TABLE 1 HERE]

\subsection{Structural Impulse Responses to Oil Price Shocks: SVAR}

First, we examine the dynamic adjustment of each uncertainty measure to unexpected structural oil price shocks as referred to Kilian and Park (2009) for the full sample period and then we will proceed with the results of the TVP-VAR. 
Figure 3 reports the accumulated impulse responses of each uncertainty series to one standard deviation structural shocks from the oil supply side, the aggregate demand of crude oil and the oil-specific demand for a time period of 24-months.

\section{[FIGURE 3 HERE]}

Starting the analysis from an unexpected positive oil supply shock (Shock 1) and specifically looking at the first column of Figure 3, we observe that none of the uncertainty indicators exhibits any significant response to oil supply shock. A plausible explanation of the non-effect of the oil supply shocks is that financial and commodities markets, as well as, economies worldwide are familiar with OPEC practices and hence, they are not "surprised" even when unanticipated oil supply disruptions or increases take place. Such finding is also in line with Kilian (2009). More specifically, OPEC usually decides not to reduce production levels to maintain its market share, as competition from other sides intensifies with undeniable example the shale oil production from the United States. The aforementioned findings find support from the existing literature, such as, Kilian and Park (2009), Kilian (2009), Hamilton (2009), Bloom (2009), Alquist and Kilian (2010), Filis et al. (2011), Stock and Watson (2012), Kang and Ratti (2013), Degiannakis et al. (2014) and Aloui et al. (2016) who maintain that disturbances from the supply-side shall result in small and transient changes in oil prices and therefore do not significantly affect economic and financial indicators. On the other hand, our findings do not confirm those by Kang et al. (2017) who maintain that supply-side shocks originating from oil supply disruptions by the US lead to an increase in EPU.

Focusing on the second column of Figure 3, we show the uncertainty responses to positive aggregate demand shocks (Shock 2). Interestingly enough the responses are not homogeneous, which suggests that the multiple faces of uncertainty within the economy could be impacted differently by oil price shocks. Hence, monitoring the different responses from each uncertainty indicators is essential in disentangling how oil price shocks propagate their effects in the different uncertainty sources of economic activity. More specifically, four out of the six uncertainty series are affected, namely the JMU, VIX, OCV and ORV; however, the latter two exhibit a significant response only in the very short-run (the response become insignificant after 3 months). Even more we find that positive aggregate demand shocks lead to negative responses from the aforementioned uncertainty indicators, except for JMU. This is rather expected as aggregate demand shocks are related to increased global 
economic activity, which can be regarded as positive news for the business and the financial sectors leading to lower uncertainty. The finding for VIX echoes this by Degiannakis et al. (2014) who maintain that European stock market volatility responds negatively to positive aggregate demand shocks. It is interesting that economic policy uncertainty (EPU) does not respond to aggregate demand shocks, which are not in line with the findings reported by Kang and Ratti (2013), Antonakakis et al. (2014) and Kang et al. (2017) who find evidence that aggregate demand shocks exercise a significantly negative effect on EPU. Such difference could lie in the fact that this study is using a different time period, which could suggest that these relationships vary depending on the time period.

Finally, the effects of an unanticipated positive oil specific demand shock (Shock 3) are presented in the third column of Figure 3. Once again heterogeneity in responses of the uncertainty indices is evident. In particular, we observe a positive response from JMU and negative responses from VIX, OCV and ORV. By contrast, no responses are observed for EPU and EMU. The results for the OCV and ORV are somewhat expected, especially when these are combined with the ORV responses to aggregate demand shocks. We maintain that oil price increases due to demand side shocks (either aggregate demand or oil specific demand shocks) tend to reduce oil price volatility due to the leverage effects ${ }^{14}$. The results for the JMU is also expected, given that increased uncertainty about the future availability of oil, which drives oil prices in higher levels, is negative news for the macroeconomic uncertainty. On the other hand though, the findings for VIX are rather counter-intuitive. Based on claim put forward for the JMU response to oil specific demand shocks, a positive response from the VIX index would be also anticipated. Overall, we do not offer support to the findings by Kang and Ratti (2013), Antonakakis et al. (2014) and Kang et al. (2017) who show that actually EPU responses positively to positive oil specific demand shocks. Nevertheless, the findings by Kang et al. (2017) suggest a marginal effect of oil specific shocks to EPU.

A plausible explanation of our findings could be that the behaviour of the uncertainty indices to oil price shocks is changing over time and thus we cannot observe similar findings with the previous literature (e.g. Kang and Ratti, 2013;

\footnotetext{
${ }^{14}$ For instance, if we estimate an asymmetric GARCH model in the daily frequency of the oil price returns, the asymmetric parameter of the conditional volatility is positive and significant at any conventional significance level.
} 
Degiannakis et al., 2014; Kang et al., 2017). In is interesting that all previous studies have used different time periods, yet similar approaches. This strengthens our argument that the aforementioned effects depend on the period under examination and thus they are time-varying. Thus, we need to proceed with the estimation of a TVPVAR, which will allow us to assess if these responses are indeed time-varying.

Apart from the impulse responses, it is interesting to examine the variance decompositions of the uncertainty indices (see Table 2).

[TABLE 2 HERE]

Table 2 reveals that for the majority of uncertainty indices the supply-side shocks do not seem to explain the forecast error variance decomposition. These findings corroborate previous findings which agree on the no-existent or marginal effects of the supply-side oil price shocks to economic and financial indicators (see, for instance, Filis et al., 2011; Stock and Watson, 2012; Kang and Ratti, 2013; Degiannakis et al., 2014; Aloui et al., 2016). By contrast, though, supply-side shocks seem to explain a high proportion of the JMU variance. Turning our attention to the two demand-side shocks, it is interesting to observe that they contribute to the variance of the two commodity uncertainty indicators and JMU at a relatively high degree (ranging between $32 \%$ and $61 \%$ on aggregate, approximately). However, such claims do not hold for the financial and policy-related uncertainty, which seem to be primarily impact by their own variance. Overall, the findings from Table 2 corroborate those of the impulse responses.

\subsection{Structural Impulse Responses to Oil Price Shocks: TVP-VAR}

Having examined the results for the full sample period, we proceed with the TVP-VAR model which allows us to investigate the impulse responses at different time periods, without estimating a model for each separate time period ${ }^{15}$.

The time-varying responses to shocks for $0,1,3,6,12$ and 18 months horizons are presented in Figures 4 and 5. We should emphasize here that for the TVP-VAR models the interpretation of the impulse responses is not clear as the one-standard-

\footnotetext{
${ }^{15}$ For brevity we do not include here the parameters estimates, the sample autocorrelation, the Geweke's CD statistics and the inefficiencies. The same holds for the stochastic volatility estimates over time. The results show that MCMC algorithm has produced the posteriors efficiently and that stochastic volatility is indeed time-varying. These are available upon request. In addition, given that figures contain the impulse responses from three different horizons, confidence intervals are not included for easier exposition. We should highlight though that we only interpret the significant impulse responses.
} 
deviation shock corresponds to shocks of different size as we move across time. Thus, we follow Nakajima (2011) and compute the impulse responses by fixing an initial shock size equal to the average of stochastic volatility over the sample period and employing the simultaneous relations at each point in time. The recursive innovation of the variable is constructed based on the estimated time-varying coefficients from the current date to future periods

\section{[FIGURES 4 and 5 HERE]}

It is evident that impulse responses vary at different time periods, which provides support to the estimation of a TVP-VAR model. Furthermore, apart from the time-varying character of the impulse responses, we observe that these responses are quite heterogeneous depending on the shock and the uncertainty indicator.

Starting from the supply-side shocks, the responses are mainly negative for all uncertainty indices, suggesting that positive supply-side shocks lead to a reduction in economic and financial uncertainty. These results hold for the short-run impulse responses (1-6 months) as in the longer-run (i.e. 12 and 18 months) the responses are insignificant. It is also interesting to note that in most cases the responses appear with one month lag, given that the immediate impulse responses are not significant. These findings are rather interesting, as they are in contrast to the majority of the studies, which report insignificant effects of supply-side shocks in the economy (see, for instance, Filis et al., 2011; Degiannakis et al., 2014; Aloui et al., 2016). Furthermore, we can observe that magnitude of the responses is not constant and in cases such as VIX and JMU a declining pattern is evident, suggesting that in the more recent years, these two uncertainty indicators do not really react to supply-side shocks (at least in the medium and long-run, from 3 up to 18 months ahead). By contrast, EMU and EPU seem to be more responsive to these shocks since 2003 .

We further our analysis with the examination of the aggregate demand shocks. In Section 4.2 we concluded that uncertainty indicators respond favourably to these shocks (i.e. positive aggregate demand shocks lead to lower uncertainty). Nevertheless, the TVP-VAR results suggest that even though a favourable response prevails (i.e. negative impulse responses), there are periods where positive aggregate demand shocks lead to increased uncertainty, especially in the medium run (between 3 and 6 months ahead). This is particularly evident in the period 2010-2014. This is a very interesting finding, which further justifies the use of a time-varying environment in order to unravel the relationship between uncertainty and oil shocks. For instance, a 
plausible explanation could be found in the fact that, in the post-GFC period, we observe that even though GEA is exhibiting a declining trend, the financial uncertainty is also reaching its lowest levels (at least in our sample period), as shown in Figure 1. The latter can be explained by the fact that in the post-GFC period we observe the financial uncertainty to be resolved and being reverted back to the precrisis levels, whereas, by contrast, the global economic activity is still in the lower part of the business cycle (see also Cesa-Bianchi et al., 2014).

We finalise the analysis with the time-varying responses to oil specific demand shocks. We show that there are periods where these shocks increase the economic and financial uncertainty, as expected, although the significant responses in some cases appear only in the short- to medium-run (i.e. up to 6 months ahead). Even more, it is evident from the impulse responses that the shocks are absorbed in the long-run as the 12 and 18 months-ahead impulse responses are insignificant. Nevertheless, we also show that there are periods where the opposite behaviour is observed, i.e. where a positive oil specific demand shock (i.e. an uncertaintygenerating source) triggers negative responses from the uncertainty indicators (i.e. reduces uncertainty) ${ }^{16}$, which is rather unexpected. More specifically, we notice that this unexpected finding is mainly associated with the latter part of our sample period. A closer investigation, though, suggests that such finding is not unexpected at all. In particular, in the post-GFC period a series of conflicts that raise geopolitical unrest (the main source of the oil specific demand shocks) have taken place (e.g. the Libyan political turmoil, the political turbulence in Egypt, Yemen, and Bahrain and the war in Syria), however, oil prices exhibited a declining pattern, which gave rise to increased speculation in the oil market and accumulation of oil reserves. Hence, due to the accumulation of these oil reserves, the oil specific shocks in the latter part of our study period do not lead to higher economic and financial uncertainty. Thus, we can conclude that the previous findings which suggest that oil specific shocks are expected to trigger higher uncertainty do not hold throughout the study period but rather responses are indeed time-varying.

\footnotetext{
${ }^{16}$ We note that the literature has documented that positive oil price shocks trigger negative responses from financial markets (i.e. negative returns). We, thus, claim that our finding is rather unexpected, given that negative returns should be associated with increased uncertainty rather than the opposite.
} 


\section{Conclusion}

This study adds to the extremely scarce literature on the effects of oil price shocks on economic and financial uncertainty. Even more, we assess whether these effects are time-varying. In particular, we focus on the US economic and financial uncertainty using monthly data over the period from January 1994 to March 2015. Economic and financial uncertainty is approximated by six indicators, namely, JMU, EPU, EMU, VIX, OCV and ORV. The study uses a Structural VAR model, similar to Kilian and Park (2009), as well as, a TVP-VAR.

The impulse responses to structural oil price shocks from the SVAR model reveal that oil supply shocks do not exercise any significant impact on uncertainty indicators. Such findings lend support to the existing literature (see, inter alia, Degiannakis et al., 2014; Antonakakis et al., 2014; Aloui et al., 2016) who argue that oil supply-side shocks do not exert a significant impact in the economy or the financial markets. Furthermore, we report that aggregate demand shocks trigger lower uncertainty, which is in line with Degiannakis et al. (2014). Finally, based on the SVAR results we cannot claim that oil specific demand shocks are uncertainty enhancing shocks.

The TVP-VAR results suggest that the responses of the uncertainty indices to the three oil price shocks are indeed time-varying and, thus, static approaches could result in counter-intuitive results. The time-varying impulse responses show that uncertainty indices exhibit heterogeneous responses to all three shocks, as well as, during different time periods. Nevertheless, we notice that for the largest part of our sample period, supply-side and aggregate demand oil price shocks tend to decrease the level of economic and financial uncertainty in the US.

We are aware that economic and financial uncertainty indicators are considered as key elements for policy making and investment decisions, and thus, our findings are important for policy makers, as well as, investors. Overall, we show that the effects of oil price shocks to the different faces of economic uncertainty are not only time-specific but also depend on the source of the uncertainty that one examines. Hence, given that oil price shocks could destabilize the policy outcome, policy makers should take into account the sources of oil price shocks at the time of the decision and the uncertainty sources that they are targeting, when making informed decisions on macroeconomic policies that resolve economic uncertainty. Furthermore, our results 
should be considered when investors make decisions regarding the investment in volatility indices or risk management strategies.

Further research could investigate as to whether oil shocks trigger timevarying responses on other economic and financial indicators. Even more, future studies could expand the scope of this analysis to the global uncertainty utilizing global uncertainty indices such as the global EPU and the geopolitical risk index. Furthermore, separating the US and non-US supply-side oil price shocks could be an interesting avenue for future research. Finally, given the increased importance of uncertainty indicators in economic and financial decision making, it is important to examine the ability of oil price shocks to improve the forecasting accuracy of these indicators.

\section{Acknowledgements}

The authors would like to thank Prof. Paresh Narayan (Editor), Prof. Russell Smyth (Associate Editor) and the seven anonymous reviewers for their helpful comments on a previous version of this paper. The usual disclaimer applies.

\section{References}

Abel, A.B., and Bernanke, B.S. (2001). Macroeconomics. Addison Wesley Longman Inc.

Aloui, R., Gupta, R., and Miller, S. M. (2016). Uncertainty and crude oil returns. Energy Economics, 55, 92-100.

Alquist, R., and Kilian, L. (2010). What Do We Learn from the Price of Crude Oil Futures? Journal of Applied Econometrics 25, 539-573.

Andersen, T. G., and Bollerslev, T. (1998). Answering the skeptics: Yes, standard volatility models do provide accurate forecasts. International Economic Review, 885-905

Andersen, T. G., Bollerslev, T., Christoffersen, P. F., and Diebold, F. X. (2006). Volatility and correlation forecasting. Handbook of Economic Forecasting 1, 777-878.

Angelidis, T., Degiannakis, S., and Filis, G. (2015). US stock market regimes and oil price shocks. Global Finance Journal 28, 132-146.

Antonakakis, N., Chatziantoniou, I., and Filis, G. (2013). Dynamic co-movements of stock market returns, implied volatility and policy uncertainty. Economics Letters, 120(1), 87-92.

Antonakakis, N., Chatziantoniou, I., and Filis, G. (2014). Dynamic Spillovers of Oil Price Shocks and Economic Policy Uncertainty. Energy Economics, 44, 433447.

Antonakakis, N., Chatziantoniou, I., and Filis, G. (2017). Oil shocks and stock markets: Dynamic connectedness under the prism of recent geopolitical and economic unrest. International Review of Financial Analysis, 50, 1-26. 
Apergis, N., and Miller, S.M. (2009). Do Structural Oil - Market Shocks Affect Stock Prices? Energy Economics 31(4), 569-575.

Bachmann, R., Elstner, S., and Sims, E.R. (2010). Uncertainty and Economic Activity: Evidence from Business Survey Data. NBER Working Papers 16143, National Bureau of Economic Research, Inc.

Baker, S.R., Bloom, N. \& Davis, S.J. (2016). Measuring economic policy uncertainty. The Quarterly Journal of Economics, 131(4), 1593-1636.

Baum, C.F., Caglayan, M., and Talavera, O. (2010). On the Sensitivity of Firms's Investment to Cash Flow and Uncertainty. Oxford Economic Papers 62(2), 286306.

Baumeister, C., and Kilian, L. (2014). What central bankers need to know about forecasting oil prices. International Economic Review 55(3), 869-889.

Bekiros, S., Gupta, R., and Paccagnini, A. (2015). Oil price forecastability and economic uncertainty. Economics Letters, 132, 125-128.

Bernanke, B.S. (2006). The Economic Outlook. Remarks before the National Italian American Foundation. New York: 2006.

Bernanke, B.S. (1983). Irreversibility, Uncertainty, and Cyclical Investment. The Quarterly Journal of Economics 98(1), 85-106.

Bloom, N. (2009). The Impact of Uncertainty Shocks. Econometrica 77, 623-685.

Bloomberg. (2017). Trump's uncertainty principle, Bloomberg Business Week 26/01/2017, https://www.bloomberg.com/news/articles/2017-01-26/trump-suncertainty-principle.

Boldanov, R., Degiannakis, S., and Filis, G. (2016). Time-varying correlation between oil and stock market volatilities: Evidence from oil-importing and oilexporting countries. International Review of Financial Analysis 48, 209-220.

Broadstock, D., and Filis, G. (2014). Oil price shocks and stock market returns: New evidence from the United States and China. Journal of International Financial Markets, Institutions and Money 33, 417-433.

Caggiano, G., Castelnuovo, E., and Figueres, J.M. (2017). Economic policy uncertainty and unemployment in the United States: A nonlinear approach. Economics Letters, 151, 31-34.

Cesa-Bianchi, A., Pesaran, M. H., \& Rebucci, A. (2014). Uncertainty and economic activity: A global perspective. Working paper in IDEAS.

Cunado, J., and de Gracia, F. P. (2014). Oil price shocks and stock market returns: Evidence for some European countries. Energy Economics 42, 365-377.

Degiannakis, S., Filis, G., and Floros, C. (2013). Oil and Stock Returns: Evidence from European Industrial Sector Indices in a Time-Varying Environment. Journal of International Financial Markets, Institutions and Money 26, 175-191.

Degiannakis, S., Filis, G., and Kizys, R. (2014). The Effects of Oil Price Shocks on Stock Market Volatility: Evidence from European Data. The Energy Journal 35(1), 35-56.

Ding, Z., Granger, C.W.J., and Engle, R.F. (1993). A Long Memory Property of Stock Market Returns and a New Model. Journal of Empirical Finance 1(1), 83106.

El Anshasy, A.A., and Bradley, M.D. (2012). Oil Prices and the Fiscal Policy Response in Oil-Exporting Countries. Journal of Policy Modeling 34(5), 605620.

Elder, J. and A. Serletis (2010). Oil Price Uncertainty. Journal of Money, Credit and Banking 42(6), 1137-1159. 
Fang, Y. (1996). Volatility Modeling and Estimation of High-Frequency Data with Gaussian Noise. PhD dissertation, MIT Sloan School of Management.

Filis, G. (2010). Macro Economy, Stock Market and Oil Prices: Do Meaningful Relationships Exist among Their Cyclical Fluctuations? Energy Economic 32(4), 877-886.

Filis, G., Degiannakis, S., and Floros, C. (2011). Dynamic Correlation between Stock Market and Oil Prices: The Case of Oil-Importing and Oil-Exporting Countries. International Review of Financial Analysis 20(3), 152-164.

Gali, J., Gambetti, L., 2015. The effects of monetary policy on stock market bubbles: Some evidence. American Economic Journal: Macroeconomics 7, 233257.

Hamilton, J.D. (1983). Oil and the Macroeconomy since World War II. Journal of Political Economy 228-248.

Hamilton, J.D. (1988). A Neoclassical Model of Unemployment and the Business Cycle. Journal of Political Economy 96, 593-617.

Hamilton, J.D. (1996). This is What Happened to the Oil Price Macroeconomy Relationship. Journal of Monetary Economics 38, 215-220.

Hamilton, J.D. (2008). Oil and the Macroeconomy. In the New Palgrave Dictionary of Economics: Eds.S. Durlauf and L. Blume, Palgrave McMillan Ltd.

Hamilton, J.D. (2009). Understanding Crude Oil Prices. Energy Journal 30(2), 179 206.

Hansen, P. R., and Lunde, A. (2005). A forecast comparison of volatility models: does anything beat a GARCH $(1,1)$ ? Journal of Applied Econometrics 20(7), 873-889.

Hooker, M.A. (1996). What Happened to the Oil Price-Macroeconomy Relationship? Journal of Monetary Economics 38, 195-213.

Hooker, M.A. (2002). Are Oil Shocks Inflationary? Asymmetric and Nonlinear Specifications versus Changes in Regime. Journal of Money, Credit and Banking 34, 540-561.

Jones, C.M., and Kaul, G. (1996). Oil and the Stock Markets. Journal of Finance 51(2), 463-491.

Jurado, K., Ludvigson, S.C., \& Ng, S. (2015). Measuring uncertainty. The American Economic Review, 105(3), 1177-1216.

Kang, W., and Ratti, R.A. (2013). Oil Shocks, Policy Uncertainty and Stock Market Return. Journal of International Financial Markets Institutions and Money 26, 305-318.

Kang, W., Lee, K. and Ratti, R.A. (2014). Economic policy uncertainty and firmlevel investment. Journal of Macroeconomics, 39, 42-53.

Kang, W., Ratti, R. A., and Vespignani, J. L. (2017). Oil price shocks and policy uncertainty: New evidence on the effects of US and non-US oil production. Energy Economics 66, 536-546.

Kilian, L. (2009). Not All Oil Price Shocks Are Alike: Disentangling Demand and Supply Shocks in the Crude Oil Market. American Economic Review 99, 10531069.

Kilian, L., and Park, C. (2009). The impact of oil price shocks on the U.S. stock market. International Economic Review 50, 1267-1287.

Koop, G., and Korobilis, D. (2010). Bayesian multivariate time series methods for empirical macroeconomics. Now Publishers Inc.

Lee, K., and Ni, S. (2002). On the Dynamic Effects of Oil Price Shocks: A Study Using Industry Level Data. Journal of Monetary Economics 49, 823-852. 
Lippi, F., and Nobili, A. (2012). Oil and the Macroeconomy: A Quantitative Structural Analysis. Journal of the European Economic Association 10(5), 10591083.

Marcus, A.A. (1981). Policy Uncertainty and Technological Innovation. The Academy of Management Review 6(3), 443-448.

Montoro, C. (2012). Oil Shocks and Optimal Monetary Policy. Macroeconomic Dynamics 16(02), 240-277.

Nakajima, J. (2011). Time-varying parameter VAR model with stochastic volatility: An overview of methodology and empirical applications. Institute for Monetary and Economic Studies, Bank of Japan, No. 11-E-09.

Nakajima, J., Kasuya, M., and Watanabe, T. (2011). Bayesian analysis of timevarying parameter vector autoregressive model for the Japanese economy and monetary policy. Journal of the Japanese and International Economies 25(3), $225-245$.

Natal, J. (2012). Monetary Policy Response to Oil Price Shocks. Journal of Money, Credit and Banking 44(1), 53-101.

New York Times. (2016). An index of uncertainty surges after 'Brexit', 29/06/2016. https://www.nytimes.com/2016/07/01/upshot/an-index-of-uncertainty-surgesafter-brexit.html?_r=0.

Park, J., and Ratti, R.A. (2008). Oil Price Shocks and Stock Markets in the U.S. and 13 European Countries. Energy Economics 30, 2587-2608.

Pindyck, R.S. (1990). Irreversibility, uncertainty, and investment. National Bureau of Economic Research, W3307.

Popescu, A., and Smets, F.R. (2010). Uncertainty, Risk-taking, and the Business Cycle in Germany. CESifo Economic Studies 56(4), 596-626.

Primiceri, G. E. (2005). Time varying structural vector autoregressions and monetary policy. The Review of Economic Studies 72(3), 821-852.

Rahman, S. and A. Serletis (2011). The Asymmetric Effects of Oil Price Shocks. Macroeconomic Dynamics 15(S3), 437-471.

Ratti, R.A., Y. Seol and K.H. Yoon (2011). Relative Energy Price and Investment by European Firms. Energy Economics 33(5), 721-731.

Rodrik, D. (1991). Policy Uncertainty and Private Investment. Journal of Development Economics 36, 229-242.

Sadorsky, P. (1999). Oil Price Shocks and Stock Market Activity. Energy Economics 21, 449-469.

Stock, J.H., and Watson, M.W. (2012). Disentangling the Channels of the 20072009 Recession. NBER Working Paper No. 18094, 1-55.

Visco, I. (2017). Financial Market Volatility and Global Policy Uncertainty: a Conundrum, Istituto Affari Internazionali, Major Challenges for Global Macroeconomic Stability - The Role of the G7, 27/03/2017. http://www.iai.it/sites/default/files/visco-dinner_address_170327.pdf.

Xekalaki, E., and Degiannakis, S. (2010). ARCH Models for Financial Applications. Wiley, New York. 


\section{Tables}

Table 1. Descriptive statistics of the series. The period spans from January 1994 to March 2015.

\begin{tabular}{lccccccccc}
\hline Series & Obs & Mean & $\begin{array}{c}\text { Std. } \\
\text { Dev. }\end{array}$ & Max. & Min. & Skew. & Kurt. & Jarque-Bera & ADF \\
\hline PROD & 254 & 0.0013 & 0.0078 & 0.0259 & -0.0249 & -0.1724 & 3.913 & $10.0917 * * *$ & $-13.764 * *$ \\
GEA & 254 & 0.0309 & 0.2703 & 0.6248 & -0.6386 & 0.2667 & 2.310 & $8.0743^{* *}$ & $-2.928^{* *}$ \\
ROIL & 254 & 0.0054 & 0.0885 & 0.2007 & -0.3109 & -0.7609 & 4.242 & $40.8410^{* * *}$ & $-13.034 * * *$ \\
JMU & 254 & 0.6499 & 0.0859 & 1.0223 & 0.5537 & 2.0165 & 8.2596 & $466.7422^{* * *}$ & $-2.761^{*}$ \\
EPU & 254 & 1.0450 & 0.3612 & 2.4512 & 0.5720 & 1.1199 & 3.586 & $56.9578^{* * *}$ & $-4.360^{* * *}$ \\
EMU & 254 & 0.7243 & 0.6207 & 4.9603 & 0.1309 & 2.7976 & 1.370 & $1547.7201 * * *$ & $-6.727 * * *$ \\
VIX & 254 & 0.2040 & 0.0807 & 0.6264 & 0.1082 & 1.8723 & 8.618 & $484.3670^{* * *}$ & $-3.708^{* * *}$ \\
OCV & 254 & 0.3381 & 0.1147 & 0.8438 & 0.1439 & 1.3976 & 6.419 & $207.2584 * * *$ & $-4.123 * * *$ \\
ORV & 140 & 0.2848 & 0.1282 & 0.9375 & 0.0998 & 2.3276 & 10.786 & $480.0866 * * *$ & $-2.582^{*}$ \\
\hline$* * *$, and *** indicate significance at $10 \%, 5 \%$ and $1 \%$ level, respectively. & & \\
\hline
\end{tabular}

Table 2. Forecast error variance decomposition. The period spans from January 1994 to March 2015.

\begin{tabular}{lcccc}
\hline Series & PROD & GEA & ROIL & Uncertainty index \\
\hline JMU & 17.6542 & 22.8411 & 13.6698 & 45.8349 \\
EPU & 0.9048 & 0.4629 & 0.8614 & 97.7709 \\
EMU & 1.9738 & 3.2303 & 0.5868 & 94.2090 \\
VIX & 5.5943 & 5.6615 & 5.9597 & 82.7845 \\
OCV & 1.2774 & 2.9209 & 30.5170 & 65.2847 \\
ORV & 0.4029 & 12.7525 & 48.0558 & 38.7889 \\
\hline
\end{tabular}

Note: We only show the 24 months ahead forecast error variance decompositions. 


\section{Figures}

Figure 1. Changes in World Oil Production (PROD), Global Real Economic Activity (GEA) and Changes in Crude Oil Prices (ROIL) from January 1994 to March 2015.

PROD

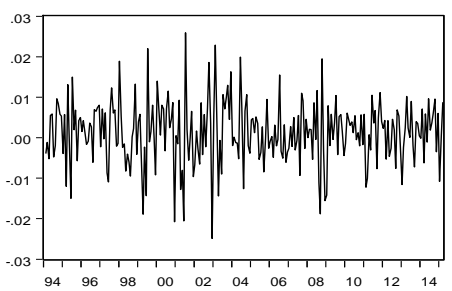

GEA

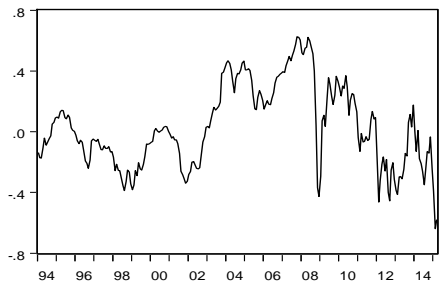

ROIL

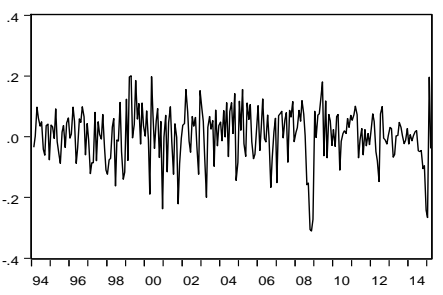

Figure 2. The US uncertainty measures and oil price volatility from January 1994 to March 2015.
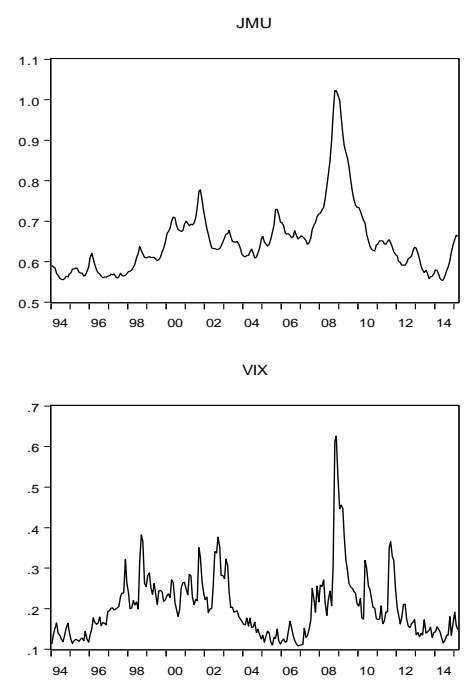

EPU

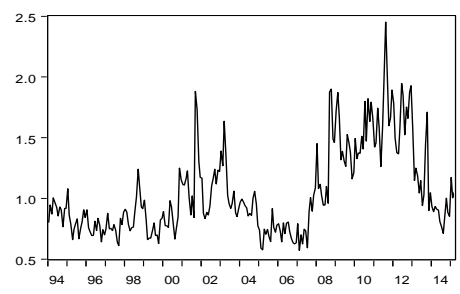

OCV

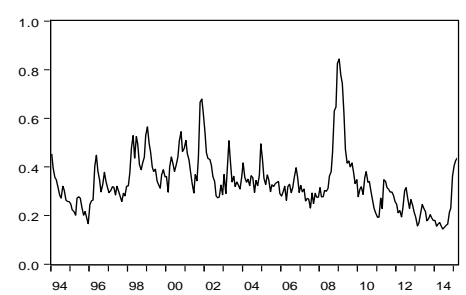

EMU

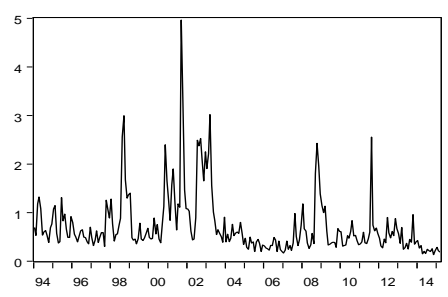

ORV

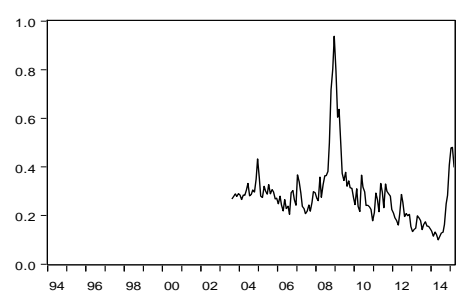

Note: JMU = Jurado's et al. (2015) Macroeconomic Uncertainty, EPU = Economic Policy Uncertainty, $\mathrm{EMU}=$ Equity Market Uncertainty Index, VIX $=$ Implied Volatility Index of S\&P500, OCV = Oil Conditional Volatility, ORV = Oil Realized Volatility. 
Figure 3. Accumulated impulse responses of the uncertainty indices to oil price shocks (Shock 1: SS, Shock 2: ADS, Shock 3: SDS), based on the SVAR model.
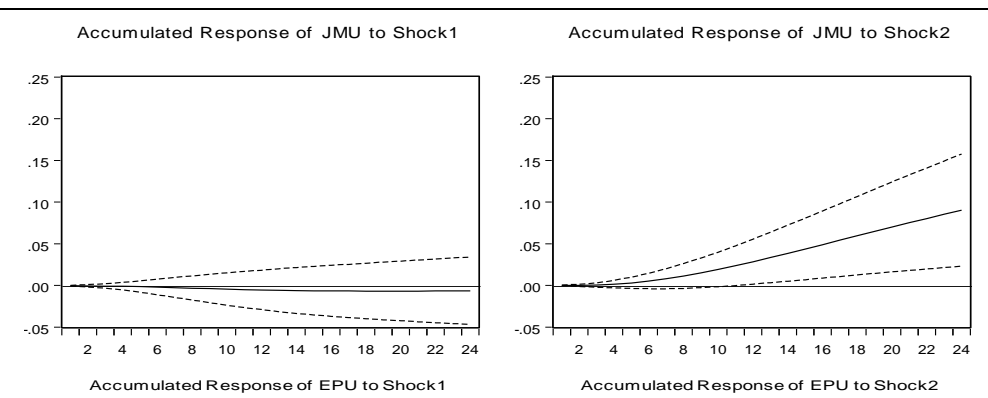

Accumulated Response of JMU to Shock3
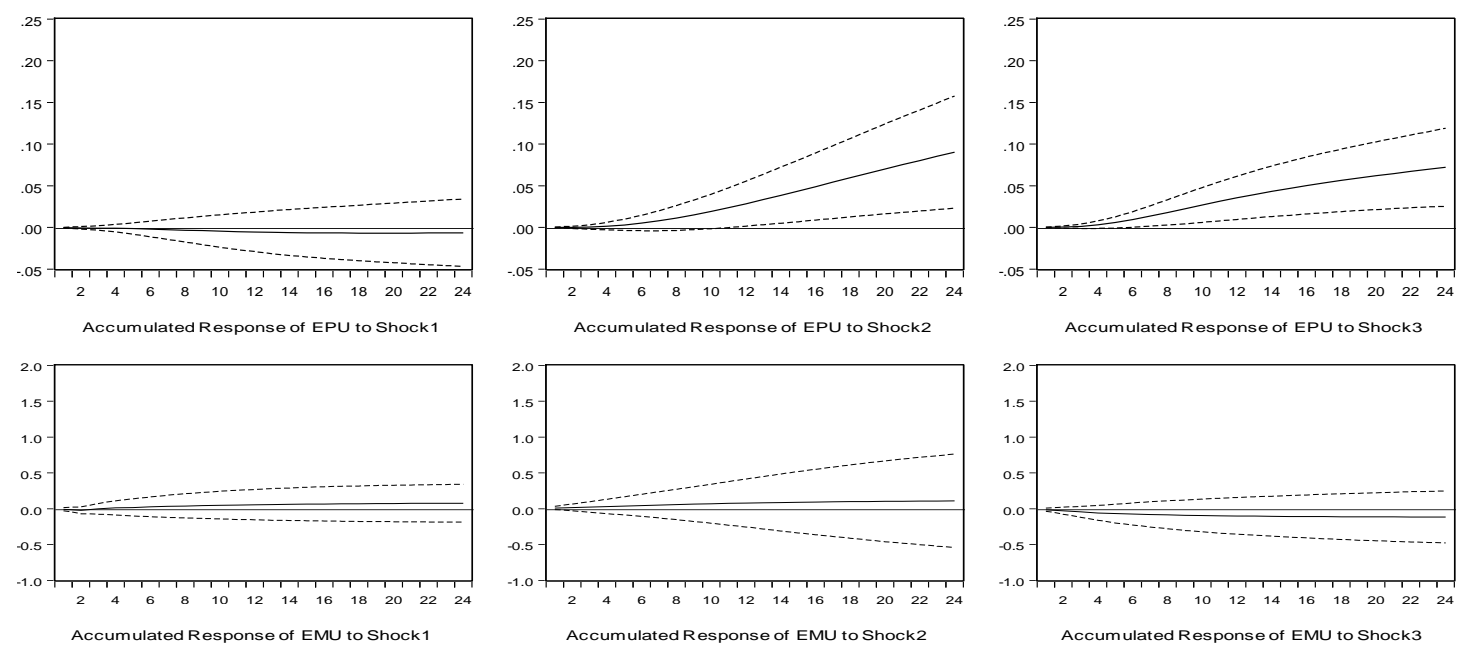

Accumulated Response of EPU to Shock 3
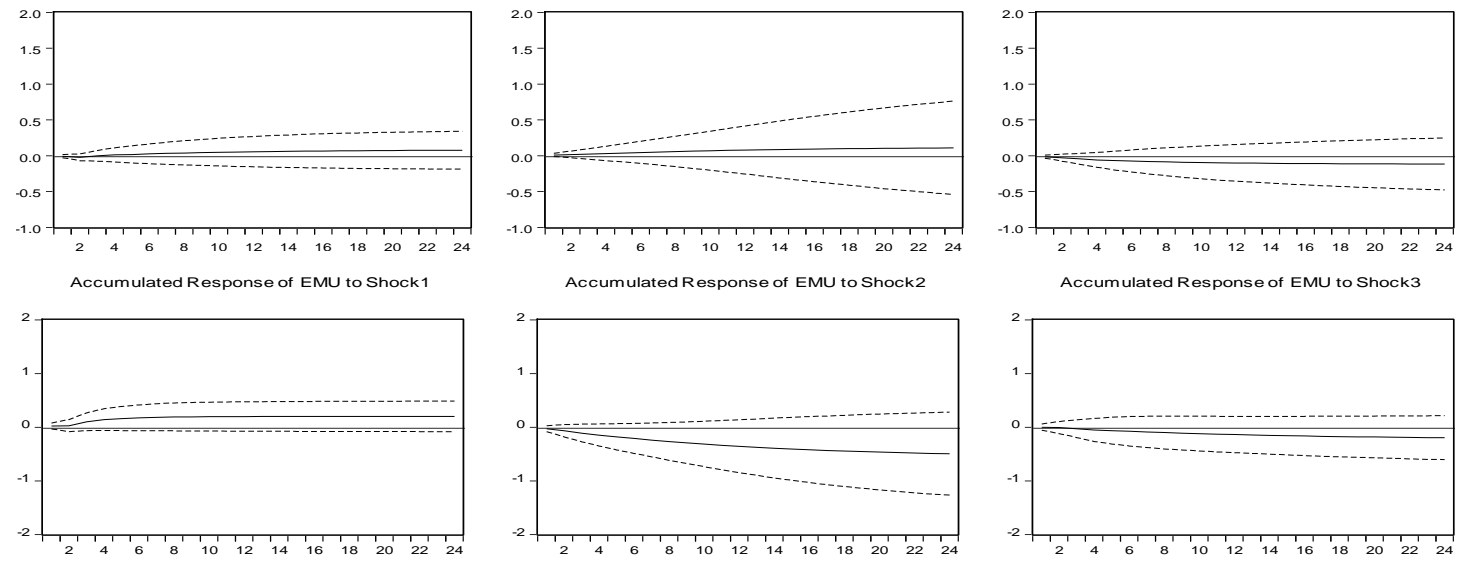

Accumulated Response of EMU to Shock3

Accumulated Response of VIX to Shock1

Accumulated Response of VIXto Shock2
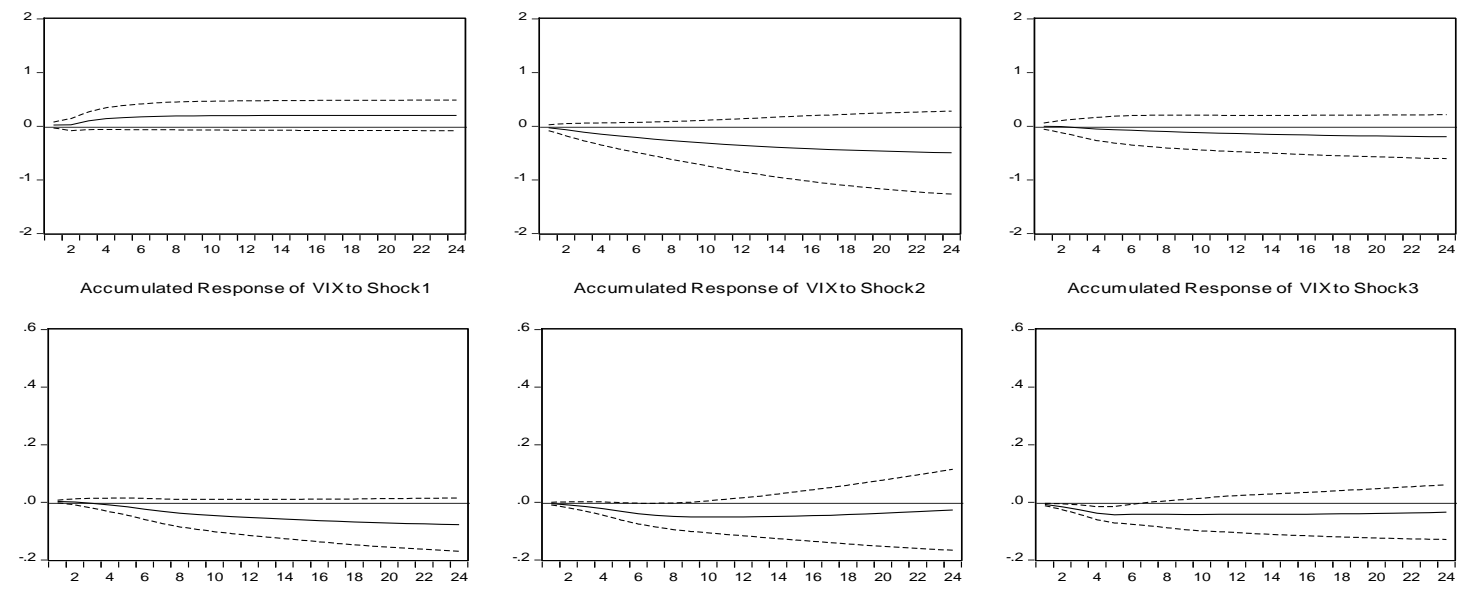

Accumulated Response of VIX to Shock3

Accumulated Response of OCV to Shock1

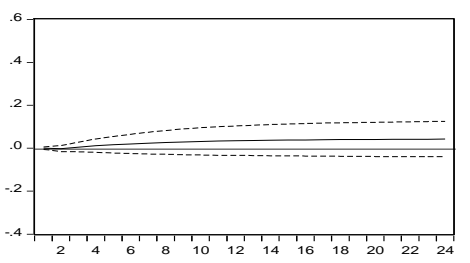

Accumulated Response of OCV to Shock2
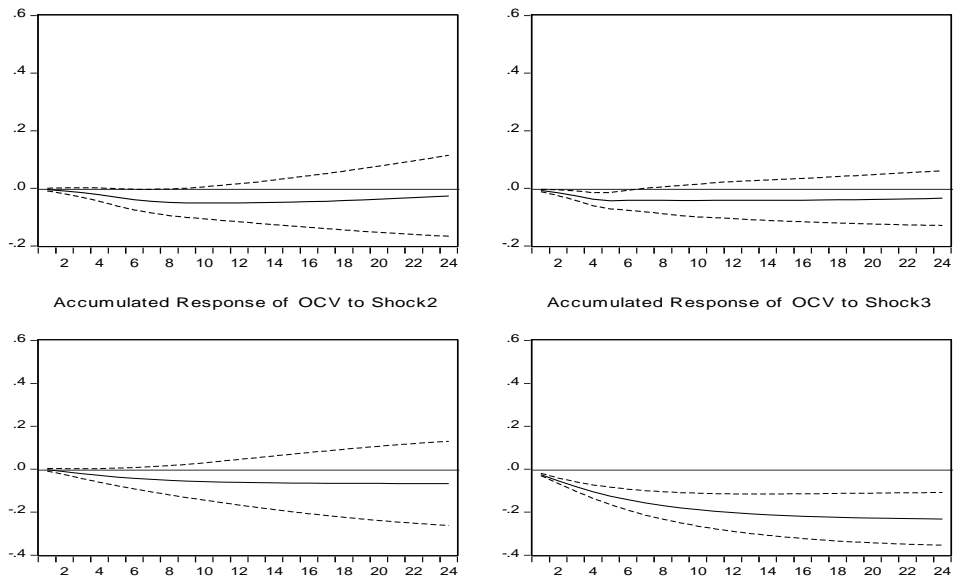

Accumulated Response of OCV to Shock3

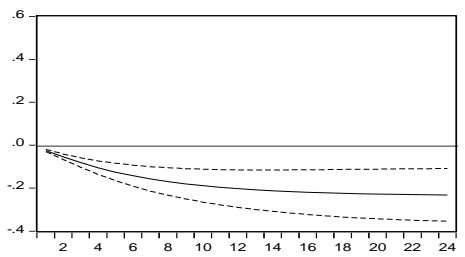

Accumulated Response of ORV to Shock 1

Accumulated Response of ORV to Shock2

Accumulated Response of ORV to Shock3
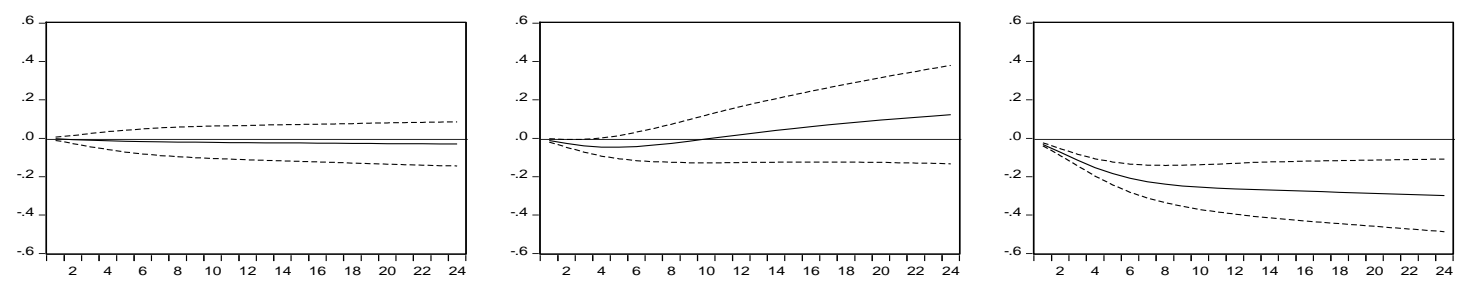

Note: Shocks successively refer to: Shock 1 to Oil Supply Shocks (SS), Shock 2 to Aggregate Oil Demand Shocks (ADS) and Shock 3 to Oil-Specific Demand Shocks (SDS). The series of the uncertainty measures (UNCERT), vertically, are the following: Jurado's et al. (2015) Macroeconomic Uncertainty (JMU), Economic Policy Uncertainty Index (EPU), Equity Market Uncertainty Index (EMU), Implied Volatility Index of S\&P500 (VIX), Oil Conditional Volatility (OCV) and Oil Realized Volatility (ORV).

Dotted lines depict the $90 \%$ confidence intervals. 
Figure 4. Impulse responses of the uncertainty indices to oil price shocks for 0,1 and 3 months ahead, based on the TVP-VAR.
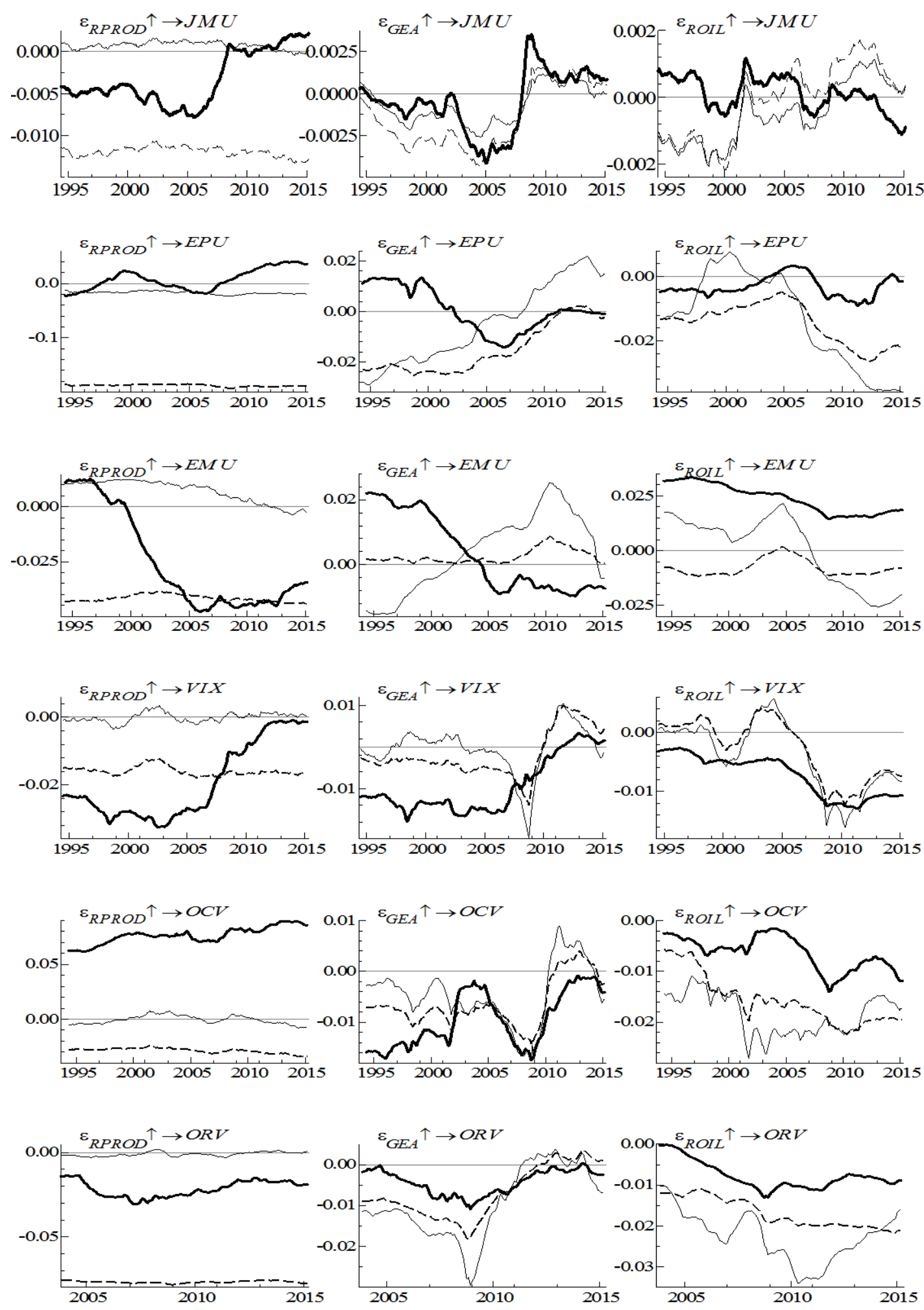

Note: The thin, dotted and bold lines correspond to the responses of the uncertainty indices to oil price shocks for 0,1 and 3 months ahead, respectively.

Impulse responses for the ORV start in 2003, whereas for the remaining uncertainty indicators the starting data of the impulse responses is 1994. 
Figure 5. Impulse responses of the uncertainty indices to oil price shocks for 6, 12 and 18 months ahead, based on the TVP-VAR.
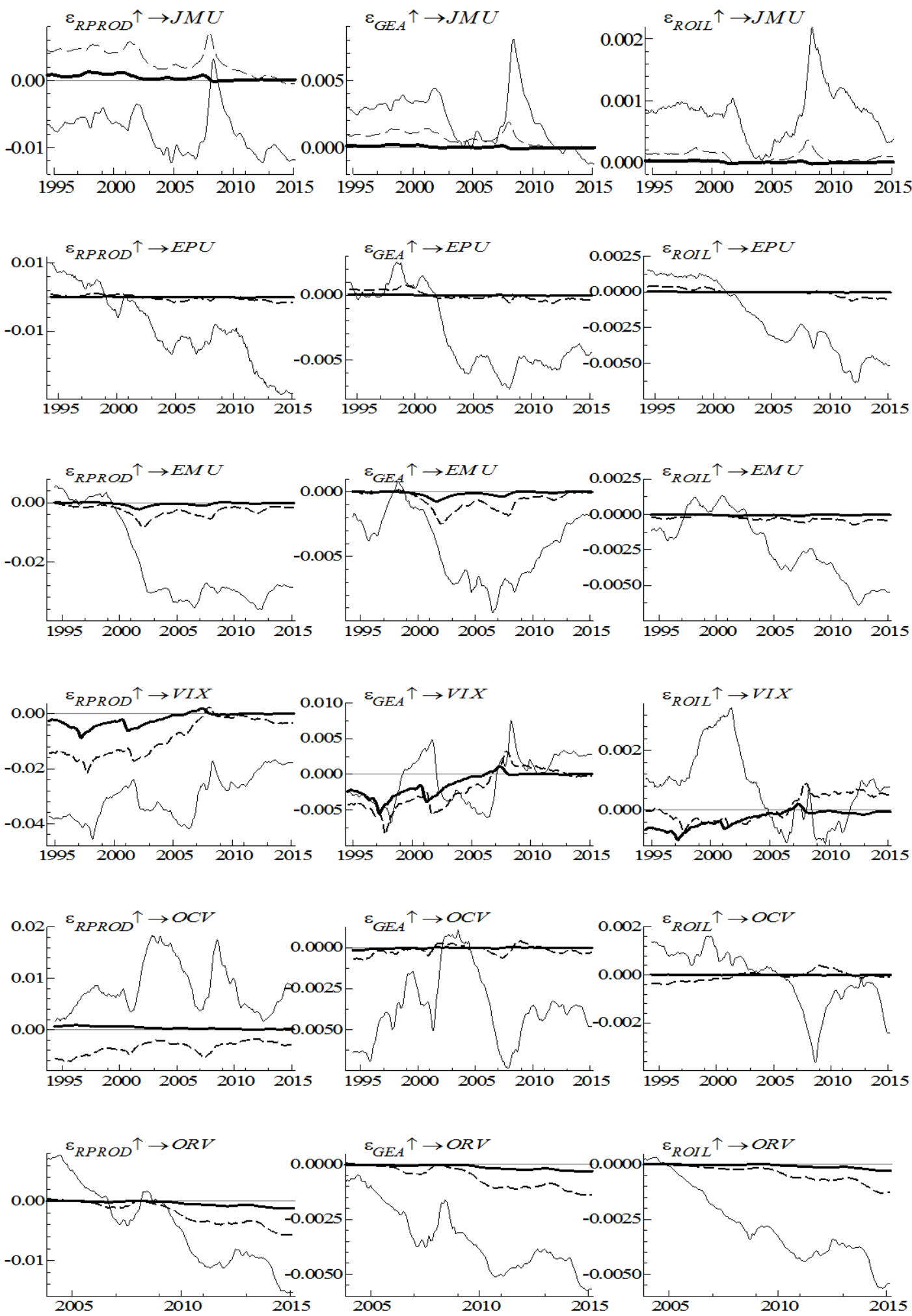

Note: The thin, dotted and bold lines correspond to the responses of the uncertainty indices to oil price shocks for 6,12 and 18 months ahead, respectively.

Impulse responses for the ORV start in 2003, whereas for the remaining uncertainty indicators the starting data of the impulse responses is 1994. 